\title{
Editorial
}

\section{Psychiatry and the arts: new interfaces? ${ }^{+}$}

\section{Jonathan Green}

Abstract I discuss the productive interface between psychiatry and the arts in the 20th century and ask whether such an interface is likely to remain as vibrant into the 21st. I review how new models of mental functioning that have an impact on current psychiatric practice have a wider cultural relevance. This editorial looks forward to a series of articles in future issues of APT which will explore some of these ideas in more detail.

\section{A 20th-century heritage}

Psychiatry and psychiatric theory enjoyed a long and distinguished interface with the arts during the 20th century. In the century characterised as 'the triumph of the therapeutic' (Rieff, 1987) it is not unreasonable to claim that psychological theory, particularly in the form of depth psychology or psychoanalysis, represented the dominant mode of art theory and criticism - certainly through the first half of the century. Some of the most perceptive visual art criticism in the English tradition in this early period used psychoanalytic and Jungian ideas (e.g. Read, 1972; Stokes, 1972). Analysts themselves often wrote on art; from many examples, Otto Rank's Art and Artist (1932) was a key early systematic text and had a foreword by the writer Anaïs Nin. Ludwig Binswanger wrote on art from the perspective of existential psychiatry, and Lacanian texts have been central to the postmodern movement. Anton Ehrenzweig (1970) made a systematic exploration of the application of general psychological theory to artistic process and his book was highly influential on artistic education and practice at that time. The visual art historian and theorist Ernst Gombrich (1960) drew extensively on gestalt and the psychology of perception. More recently, among many others, are Adam Phillips' sensitive writings

'See pp. 167-171 and 182, this issue. from the perspective of Winnicott and modern analytic theory, largely addressing literature but also photography (e.g. Phillips, 2001). Artistic practice has been systematically deconstructed from just about every psychological perspective during this past century - sometimes illuminatingly, sometimes reductively; but psychological theory has never been far from the centre of art discussion.

For artists themselves, the way in which the psychotherapeutic approach infiltrated the culture has had a profound impact: it underlay aspects of the early modernist and surrealist movements, as well as legitimising expressionism; it provided a sustained metaphor for the relationship between surface and depth - manifest and latent aesthetic meaning. In addition, extreme mental states - the art of the 'outsider' and the mentally disturbed - became an object of interest as another form of 'primitivism'. There have been parallel developments in the use of art as therapy for mental disorder.

As the general culture has become more attuned to this mode of thinking, psychiatrists and psychologists have been drawn in as cultural authorities. Films about recognisable disorders (for instance Rain Man, A Beautiful Mind, The Lost Weekend) have become fashionable, although the concepts of mental illness that they represent are often either sentimentalised or caricatures. Readers will be able to supply many other contemporary examples in the popular media, from resident psychologists on television's Big Brother and The Jeremy Kyle Show to toddler taming and brat camps.

Jonathan Green is Professor of Child Psychiatry at the University of Manchester, and Honorary Consultant Child Psychiatrist to Manchester Children's Hospitals Trust. He was academic secretary to the Child and Adolescent Faculty of the College from 1994 to 2001 and contributor to the Mind Odyssey conference 2001. His research has included work on autism, early relationships and the systematic analysis of young children's drawings. His early education in addition to medicine included a Part II Tripos in the History of Art at Cambridge University and a brief period of art school training in Paris and Winchester. He continues to paint alongside medicine and contributed to the recent College 'Art on the Stairs' scheme. 


\section{What of the 21st century?}

With this background, what of the 21st century? What may be the interface with contemporary art of more recent conceptions of mental health, mental functioning and psychiatric practice? Does the interface have as much potential as it has had previously? Psychiatry is largely at a time of empirically based pragmatic micro-theory rather than grand overarching explanations: perhaps there will be less room now for broad applications across the cultural sweep? Or should this interface be an ongoing and vital territory of mental health thinking? An additional question is why such considerations should have a place in a journal such as APT or in the general psychiatric professional literature.

Personally, I think there are plenty of reasons why the interface between psychiatry and art is still worth considering. First, it is surely inevitable that research and practice in mental health will continue to have a powerful impact on our cultural understanding of mind and behaviour and thus inform the culture out of which art of all kinds arises. Second, many aspects of artistic practice continue to explore territory similar to that explored by psychiatry, even if from a different perspective and with different methods. Psychiatry may therefore continue to find ways to learn from the arts about current approaches to mind, relationships and psychological development. Third, psychiatrists are likely to continue to be asked to provide expert cultural commentary in relation to mental illness: this is arguably a continuing part of their public education function. The vibrancy of interest in the '2001: A Mind Odyssey' initiative of the Royal College of Psychiatrists (www.rcpsych. ac.uk/campaigns/2001amindodyssey.aspx) bears witness to the continuing vigour of this interplay.

In the rest of this editorial I will briefly indicate just a few (selected) areas that may be of interest going forward. Future issues of APT will present articles that take a more in-depth look at topics relating to the current and future interface of psychiatry in the arts, particularly in relation to the media of literature, film, visual art and music and more general themes in education and philosophy.

\section{Neuroscience, mind and self}

The rise in the salience of neuroscience is bound to have interesting and unpredictable repercussions on cultural attitudes towards self and experience - which will be reflected in art. Despite arguments that the application of neuroscience in this way represents a reductionist 'neuromythology' (Tallis, 2004), the tide of new research with implications for self-concept seems to have unstoppable momentum
(Greenfield, 2002). We can surely expect more functional magnetic resonance imaging studies claiming to identify the neurobiological locus of creativity and creative perception. However, nuanced models of gene-environment interaction are likely to give more sophisticated and lasting models of mental functioning. For instance, research from developmental psychiatry into gene-environment interplay in the formation of personality and behaviour is likely to have profound consequences for our cultural narratives of self. Evidence on the interaction between early experience and gene alleles affecting dopamine and serotonin activity will inevitably find its way into the literature and art of antisocial behaviour; just as different ideas on the same subject did in previous generations for Robert Louis Stephenson and Truman Capote. Emerging models indicating differential biological susceptibility to environmental influence are bound to have an impact on the current assumptions on which most biographies are based.

As another example, since the film Rain Man and an explosion of writing by individuals who have autistic-spectrum disorders, the neuroscience and particular experience of autism has begun to fascinate cultural commentators as well as developmental scientists. The notion (and metaphor) of autism has entered the culture. The paradoxical relationship of autism to creativity is a particularly interesting issue here. There are many ways in which the two should, in theory, be incompatible (for instance the difficulties with cognitive 'central coherence' typical in autism should make difficult the deep synthetic coherence of good art). Yet in practice there is widespread fascination with the claim that numerous successfully creative people, from Newton to Bartok, had autistic traits (Fitzgerald, 2003). There is debate about whether this kind of 'psychobiography' is either evidentially rigorous or theoretically useful about creativity. At worst, autism is being used here in an overextended and reductive way as the most recent cultural explanation for the creative outsider. At best, something interesting is being said about social knowledge and creation. Either way, it is an example of a neuroscience paradigm attempting to explain creativity, precisely in the way psychoanalysis has done previously.

\section{Psychological theory}

Psychiatry can take great credit for crucial advances in the description and understanding of post-traumatic states and (with paediatrics) the recognition of the prevalence and impact of early traumatic abuse of children. These have represented some of the key social phenomena of the second part of the 20th 
century, with huge impacts on general culture and art. 'Trauma narratives' are now pervasive in all media - indeed are arguably the dominant mode of the age - and link to psychological and political themes. Examples can be seen in the rise of confessional literature about early abuse (Dave Pelzer's It boy), films with abuse as their core narrative (ubiquitous), the use of images of abuse and trauma in visual art (Jake and Dinos Chapman, Louise Bourgeois). Indeed one could argue that, in popular culture, the covert or overt impact of trauma has replaced that of the 'unconscious' as a prime explanatory model of psychological motivation. Does this help or hinder the psychiatrist's work? It can be seen as a further twist in the 'triumph of the therapeutic' but the psychological accuracy of these depictions will inevitably vary and sometimes be sensationalised. Are there downsides - for instance an underplaying of individual difference and resilience in the life course?

The notion of the subliminal or 'unconscious' motivation had cultural roots before Freud (Whyte, 1979), which gave psychoanalysis a profound resonance. As the influence of psychoanalysis on psychiatric practice has waned, its influence in the general culture has, if anything, increased. How is this likely to go in the future? Contemporary psychodynamic theory still has much to say about art: selfpsychology, Winnicott's transitional object theory, evolutionary psychology and attachment theory all give routes into understanding the meaning of art and artistic activity; any psychological theory of mind will have to include creativity.

\section{Postmodernism and a unitary self}

Can art help us understand and do psychiatry better? A central component of postmodern art practice over the past 30 years has been an irony, reflexiveness and distancing from the single authorial voice. This finds a parallel in the psychology of unstable, multiple or contextual selves. Since it is arguable that current notions of self witnessed in the art gallery or theatre often have rather more sophistication than that in common use in the psychiatric clinic, could contemporary art help psychiatrists better articulate notions of reflexiveness and personality in their work? I imagine many readers will have personal examples here. A current favourite of mine is the photographic art of Cindy Sherman. The overt content of Sherman's multiple photographic series is usually women in a variety of 'iconic' poses or situations, such as pin-ups or fashion models, domestic drudges, rebellious teens and films idols. As one looks more closely it is apparent that, curiously, each is Sherman herself, cleverly made up and acting the role. Looking longer, a number of more troubling complexities are revealed. She subtly presents each image within a context that undermines it, at the same time engaging the viewer reflexively in a disturbing sense of what he or she might be assuming, enjoying or judging while looking. The image, one's look as a viewer, her look at the viewer, one's self-awareness of one's look - over multiple images all this challenges in the most subtle way how we create, judge and react to identity in ourselves and others. Her skillful subversion of common themes and stereotypes creates a particularly unsettling and enlightening sense of provisional reality: a good counterbalance to easy diagnostic labels.

\section{Representations of mental illness}

Psychiatrists seemingly have an endless explanatory and advocacy role concerning cultural representations of mental illness. Even the most sophisticated cultural commentators reach for clichés of 'madness' soon after 'badness' in trying to explain culturally baffling events - from suicide bombers to US foreign policy. It still amazes me how crude public discussion is here and how stigmatising; how little inroad a more informed notion of mental illness has made into culturally convenient but still almost medieval concepts. There must be a continuing role here, alongside the powerful antistigma campaigns such as 'Changing Minds', which the College recently mounted (www.rcpsych.ac.uk/ campaigns/changingminds.aspx). It will be useful to review whether the representations of mental illness in films and other media have really developed in sophistication or not (an this issue that, it is hoped, will be tackled in a future article in APT).

\section{The current role of the humanities in psychiatry education}

Over the past decade there has been a firm shift towards rigorous science as a basis for stable knowledge and educational practice in psychiatry. Paradoxically, elsewhere in medicine a concurrent rise in 'medical humanities' has been evident. Just as psychiatry is divesting itself of many elements in education to do with narrative experiential methods, in other areas of medicine these are increasingly fashionable. Is there some sort of cultural cycle here in which psychiatry is moving out of sync (ahead of?) with other disciplines? If so this must be bad for the interface between psychiatry and the rest of medicine and for the impact of the psychiatric dimension in general medical education. What should be the role 
of the humanities in educating young psychiatrists? Can the study of ten good novels teach as much about human nature and mental states as shelves of psychiatry textbooks - as one of my teachers maintained? More likely, the two approaches are complementary. However, there is no defined role for the humanities in current curricula. This is another issue that it is hoped will be discussed in APT.

\section{Summary}

Does an interface with the arts really have any ongoing relevance to contemporary psychiatry? Is it still useful (if it ever was) for psychiatrists to attempt to bridge the 'two cultures'? Psychiatry remains at heart concerned with subjective experience, consciousness and extreme mental states; the arts are frequently concerned with the same things. Both work with implicit models of self and motivation and both are rooted in a common social culture. But this alone does not necessitate or ensure a productive interface. One might argue cynically that some current attempts to generate interfaces between science and art (such as the Wellcome Trust's SciArt initiative) merely legitimise poor art or give an essentially irrelevant aesthetic glow to otherwise utilitarian science. However, it is possible to discern (perhaps most clearly with historical perspective) deeper cultural commonalities and more subliminal cross-fertilisation between art and science, suggesting social and cultural development across a broad front. Waddington (1970) penetratingly suggested such processes at work in his study of the relationships between developments in modern physics and quantum theory at the beginning of the 20th century and concurrent cultural revolutions in visual art related to cubism, abstraction and modernism. This kind of work speaks against a notion of 'two cultures' at all; and also against the idea, championed by Lewis Wolpert (2000), that science (because of its very particular methods) is inherently an odd or very different activity from the humanistic arts (although both will often challenge everyday 'common sense').

I suggest that if psychiatry is properly considered, this interface should be very much alive; that continuing professional efforts in mental health plough in essentially the same field as much art; and that science and art are often convergent intellectual and cultural enterprises despite their very divergent methods. Forthcoming articles in APT will consider such themes in more detail and will, I hope, stimulate ongoing thinking and debate about how psychiatry will relate to general culture in the next decades.

\section{Declaration of interest}

None.

\section{References}

Ehrenzweig, A. (1970) The Hidden Order of Art: A Study in the Psychology of Artistic Imagination. Paladin.

Fitzgerald, M. (2003) Autism and Creativity: Is There a Link between Autism in Men and Exceptional Ability? Bruner-Routledge.

Gombrich, E. (1960) Art and Illusion: A Study in the Psychology of Pictorial Representation. Phaidon Press.

Greenfield, S. (2002) The Private Life of the Brain. Penguin.

Pelzer, D. (2000) A Child Called 'It'. Orion.

Phillips, A. (2001) Promises, Promises: Essays on Literature and Psychoanalysis. Basic Books.

Rank, O. (1932) Art and Artist: Creative Urge and Personality Development. Agathon Press.

Read, H. (1972) The Meaning of Art. Faber \& Faber.

Rieff, P. (1987) The Triumph of the Therapeutic: Uses of Faith after Freud. University of Chicago Press.

Stokes, A. D. (1972) The Image in Form: Selected Writings of Adrian Stokes (ed. R. Wollheim). HarperCollins.

Tallis, R. (2004) Why the Mind is Not a Supercomputer: A Pocket Lexicon of Neuromythology. Imprint Academic.

Waddington, C. H. (1970) Behind Appearance: A Study of the Relations between Painting and the Natural Sciences in this Century. MIT Press.

Whyte, L. L. (1979) The Unconscious before Freud. Macmillan.

Wolpert, L. (2000) The Unnatural Nature of Science. Faber \& Faber. 